\title{
Detection of sinkhole occurrence, experiences from South Africa
}

\author{
Maria Ferentinou ${ }^{1}$, Wojciech Witkowski ${ }^{2}$, Ryszard Hejmanowski ${ }^{2}$, Hennie Grobler $^{3}$, and \\ Agnieszka Malinowska ${ }^{2}$ \\ ${ }^{1}$ Department of Civil Engineering Science, University of Johannesburg, \\ Johannesburg, 2006, RSA, South Africa \\ ${ }^{2}$ Department of Mining Areas Protection, Geoinformatic and Mining Surveying, \\ AGH University of Science and Technology, Krakow, 30-059, Poland \\ ${ }^{3}$ Department of Mining and Mine Surveying, University of Johannesburg, \\ Johannesburg, 2006, RSA, South Africa
}

Correspondence: Maria Ferentinou (mferentinou@uj.ac.za)

Published: 22 April 2020

\begin{abstract}
Sinkholes are alarming and dangerous events, they have a worldwide occurrence, and are imposing a potential risk to urban communities and the widely developed built environment. Losses due to catastrophic sinkhole collapse, foundation, pavement and structural repairs, occur more often, due to the increased pressure to develop even on sinkhole prone land, and the aging of existing water supply infrastructure in the majority of cities. Remote sensing earth observation methods have proved to be valuable tools during the last two decades in long-term sinkhole hazard assessment. Satellite air borne and ground earth observation methods have primarily facilitated the wide detection of continuous displacement on the earth's crust. National sinkholes catalogues are necessary for town planers decision makers, and government authorities. In many instances the ground collapse is the result of water ingress from old poorly maintained leaking pipelines, or extensive dewatering activities. In the current study a comprehensive review of the current literature is presented in order to show experiences from South Africa and present recent mapping using PSInSAR methodology in Centurion South Africa.
\end{abstract}

\section{Introduction}

Sinkholes are considered a dangerous natural and man-made hazard, affecting transportation and infrastructure networks, responsible for property loss and fatalities, in regions underlain by soluble bedrock. In South Africa, large parts of the urban fabric between Pretoria and Johannesburg are situated on Proterozoic dolomites of the Malmani Subgroup (Chuniespoort Group, Transvaal Supergroup) formed in the Transvaal Basin. During the previous decades, in the Far West Rand, sinkholes occurrence was induced by extensive dewatering of dolomite groundwater compartments due to mining and resulted into the loss of life of 38 people (De Bruyn and Bell, 2001). A community of approximately 30000 households was relocated to safer ground in a dolomite area west of Johannesburg, at a cost exceeding USD 600 million (Buttrick et al., 2011).The rhythm of de- velopment of these densely populated areas is on the rise, as these megacities serve as the economical core of the country, increasing the risks posed by surface subsidence and sinkholes. Tshwane municipality also sources more than 40 million litters of drinking water per day $(5 \%-8 \%$ of requirements) from the dolomite aquifers, (Dippenaar et al., 2019). Nof et al. (2019) propose that sinkhole potential maps are mandatory for the planning and licensing of new infrastructure. The necessity for effective monitoring and installation of early warning systems is required to reduce the risk for people, infrastructure, and property. In the current study we present on the findings of the application of PSInSAR in the Centurion area South Africa and underline the potential of the PSInSAR method for the monitoring and assessing susceptible to sinkhole hazard urban areas. 


\section{Mechanism of sinkhole formation}

A sinkhole is defined as a feature whose surface expression may occur suddenly and manifests as a hole in the ground that is typically circular in plan view. In international literature the term sinkhole is often synonymous with doline (SANS1936, 2012). A subsidence is defined as a shallow enclosed depression that occurs slowly over time and may typically be circular, oval or linear in plan (SANS, 1936, 2012). The process of sinkhole formation is continuous dissolution of sub terrain soluble rocks, progressively leading to the development of cavities. When the soil above these cavities reach critical conditions (soil material exceeds shear strength), soil collapses, as a result of reduction of soil vertical stress. Main causes of underground cavities are the ingress of water, the lowering of groundwater table, or extensive pumping leading to dewatering (Intrieri et al., 2015; Dippenar et al., 2019). An idealized profile in karst is illustrated in Sowers (1996). One can recognize the succession of the layers from the surface downwards to the dome and the soluble bedrock. Intrieri et al. (2015) rank among sinkhole predisposing factors, as the most dominant factor the lithology i.e. the presence of soluble rocks subject to karstic processes, followed by the pre-existence man made underground cavities, of low geomechanical properties of the bedrock, and (acidic) groundwater circulation promoting the dissolution of evaporate and carbonate rocks.

The triggering is attributed to the input of water into the ground which in return contributes to increase the load of the soil material deposited in the vadose zone. This as a result may reduce the geomechanical strength of the soils and promote internal erosion and dissolution processes (Gutiérrezet al., 2009).

\section{Remote sensing and sinkhole hazard}

As part of the process of sinkhole risk management, hazard evaluation, and susceptibility mapping sinkhole inventories or catalogues need to be compiled as reliably as possible. Satellite and airborne imaging technologies offered geoscientists the opportunity to collect valuable data, which serve as input to sinkhole hazard assessment models in a short period of time and under a cost-effective way. Remote sensing methods both satellite, and airborne imaging have been widely used to support sinkhole susceptibility assessment. The use of these methods either supports the compilation of extensive sinkhole catalogues or focuses on to the detection of indicators as precursor phenomena. Interferometric synthetic aperture radar (InSAR) and its derivatives have proved to be the most valuable and widely used method in sinkhole mapping and long-term deformation monitoring (Gutierrez et al., 2014; Vaccari et al., 2018). According to Vaccari et al. (2018), challenges associated with these big datasets are primarily the development of analysis tools that can synthe-

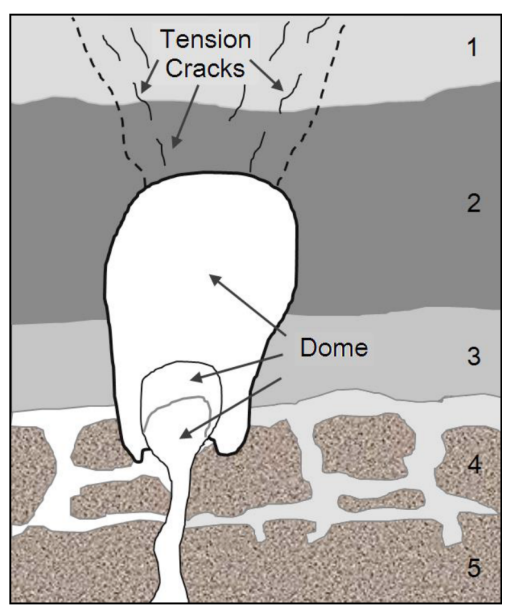

Figure 1. Idealized subsurface profile in karst, with enlarging soil void or dome above bedrock after Sowers (1996). (1) Remoulded structureless layer with highly variable stiffness; (2) over consolidated residual soil; (3) normally or lightly over consolidated residual soil; (4) randomly distributed rock pinnacles, rock blocks with soft soils, and voids or soil domes; and (5) hydraulically active competent limestone.

size them into products meaningful to the geotechnical community.

InSAR according to Rosen et al. (2000), operates by relating the coherent phase difference between radar echoes collected from the same point on the ground at two different observation times to the path-length difference between the aircraft and the ground, enabling highly accurate measurement of surface displacement in the line-of-sight direction. Only the cumulative displacement that occurred during the time interval between the imaging is measured, InSAR cannot detect movement perpendicular to the imaging plane, but along the line of sight (LOS).

Further methods and algorithms were developed to remove topographic and atmospheric effects from the derived interferogram. The use of Differential InSAR (DInSAR) takes into account the digital elevation model (DEM) of the imaged area to remove the topographic effects. As a result, the deformation along LOS of the satellite is quantified. An advanced DInSAR technique named permanent/persistent scattered InSAR (PSInSAR) was introduced (Ferretti et al., 2011), to resolve atmospheric interference problems. Vaccari et al. (2018) state that for those locations (permanent/persistent scatterer - PS) that have a large signal-tonoise ratio across several SAR images, PSInSAR can deliver deformation measurements with an accuracy of less than 1 $\mathrm{cm}$. PS method gives better results, when features such as rocky outcrops, lamp posts, crash barriers, transmission towers, fences, buildings exist in the imaged area. Thus, in rural areas, the density of PS can be extremely low. The introduction of an improved version of PSInSAR, SqueeSAR (10) usually refers to as the second generation of PSInSar, with 


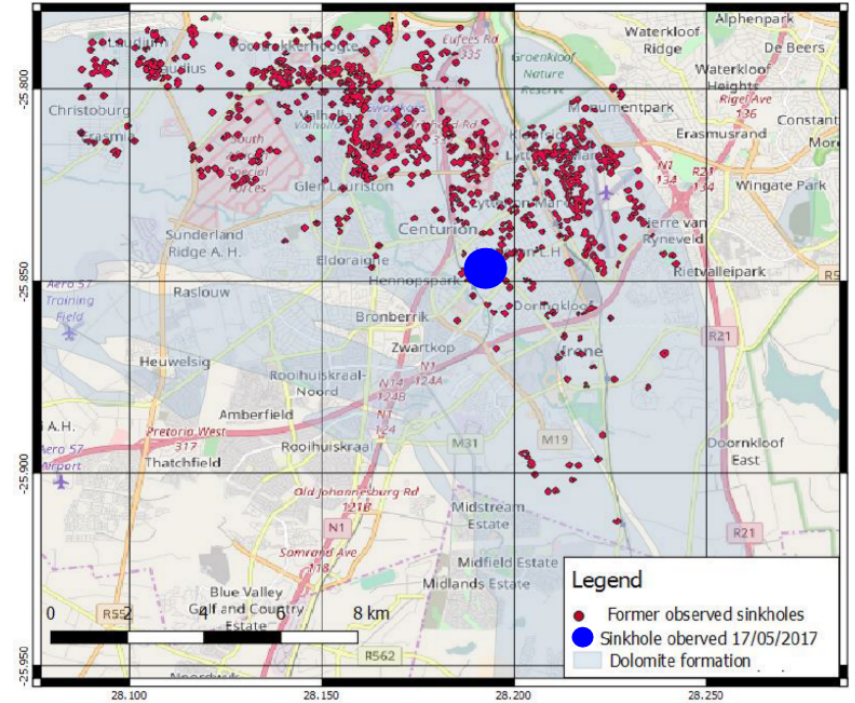

Figure 2. Distribution of sinkholes occurrences in the region of Centurion, CBD area, early 1970s-mid-2012 (Oosthuizen and Richardson, 2011), (O) OpenStreetMap contributors 2019. Distributed under a Creative Commons BY-SA License Planet dump (Data file from 1 October 2019 of database Geofabrik). Retrieved from https://planet.openstreetmap.org.

an additional layer of statistical analysis is used to identify regions providing a consistent and traceable response to the radar pulses over time.

However, the literature documenting detection of precursor phenomena through remote sensing is very limited. Many researchers (Intrieri et al., 2015; Gutiérrez et al., 2019; Malinowska et al., 2019), mention, that there is a need for an identification of precursory deformation prior to the catastrophic main sinkhole events. Baer et al. (2018) suggest that the temporal relationships between subsidence and sinkhole collapse and particularly the factors controlling the duration of the precursory subsidence are still poorly understood.

\section{PSInSAR application in Centurion}

Persistent Scatterers (PS) as previously discussed, is a multiinterferometric technique which enables to generate displacement time-series for chosen radar targets. The general assumption of PS model is a linear temporal velocity of ground movement (Ferreti et al., 2011). Based on this assumption the reliability of ground motion observation allows to be described through standard deviation. The accuracy of PS method ranges from $0.1-1 \mathrm{~mm} \mathrm{yr}^{-1}$ in the LOS direction (Colesanti et al., 2003). One of the challenges when applying this method is that PS with high standard deviation values could present process artefacts due to low signal-to noise ratio or non-linear motion. Thus, the analysis of spatial correlation among PS with high standard deviation could lead to

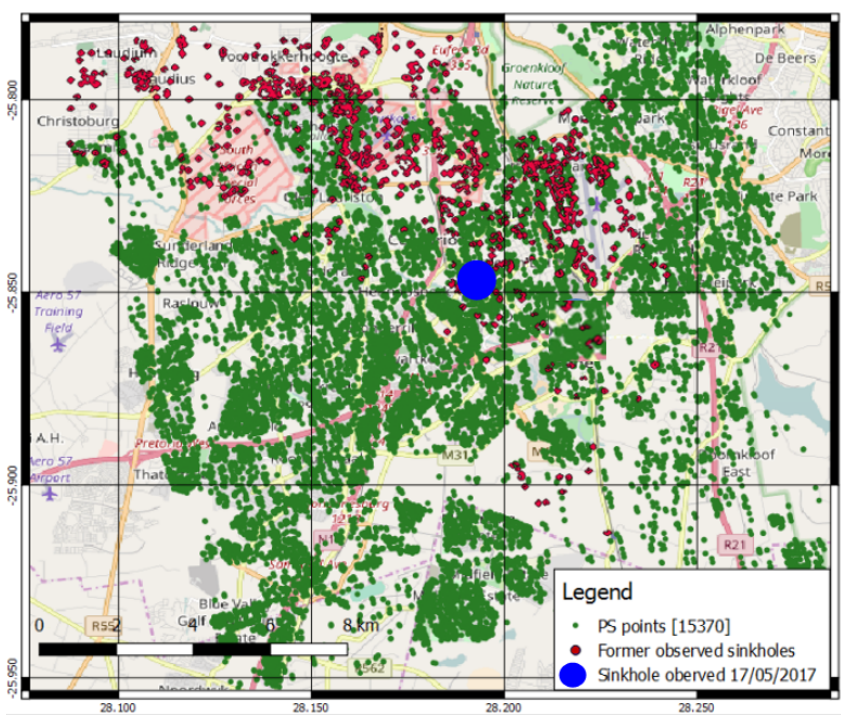

Figure 3. Coverage of the study area with PS point's overlaid on former observed sinkhole events, (COpenStreetMap contributors 2019. Distributed under a Creative Commons BY-SA License. Planet dump (Data file from 1 October 2019 of database Geofabrik). Retrieved from https://planet.openstreetmap.org.

identification of zones with non-linear displacement velocities.

On the 17 May 2017 a massive sinkhole occurred in the densely built-up area on the corner of Gerhard Street and Jean Avenue, in Centurion. In Fig. 2 the spatial distribution of 1100 events that occurred during the last four decades in the area south of Pretoria (Oosthuizen and Richardson, 2011). The occurrence of this event was a motivation to extend the research on sinkhole prone areas identification for the Centurion region. The analysis was aimed at investigating the possible evidence of subtle movement related to the known sinkholes in the area.

Ground movements were established based on Sentinel1A images acquired from the European Space Agency (ESA). The images were acquired every $12 \mathrm{~d}$ from ascending and descending orbits. The interferometric wide swath mode cover was of $250 \mathrm{~km}$. The medium resolution was at a range of 5 to $20 \mathrm{~m}$ and azimuth direction (ESA, 2013). The vertical displacements were analysed for the period between May 2015 to May 2017. For this study 12 and 24 scenes have been acquired respectively from Sentinel-1satellite. The perpendicular baseline is given with respect to the master image acquired at 18 April 2007. The interferograms were generated using the software SNAP and SNAPHU (ESA, 2017).

\section{Results}

For the processed data, we observe a good number of PS objects generally uniformly distributed over the study area. The density of the PS was high mostly due to fact that study area 


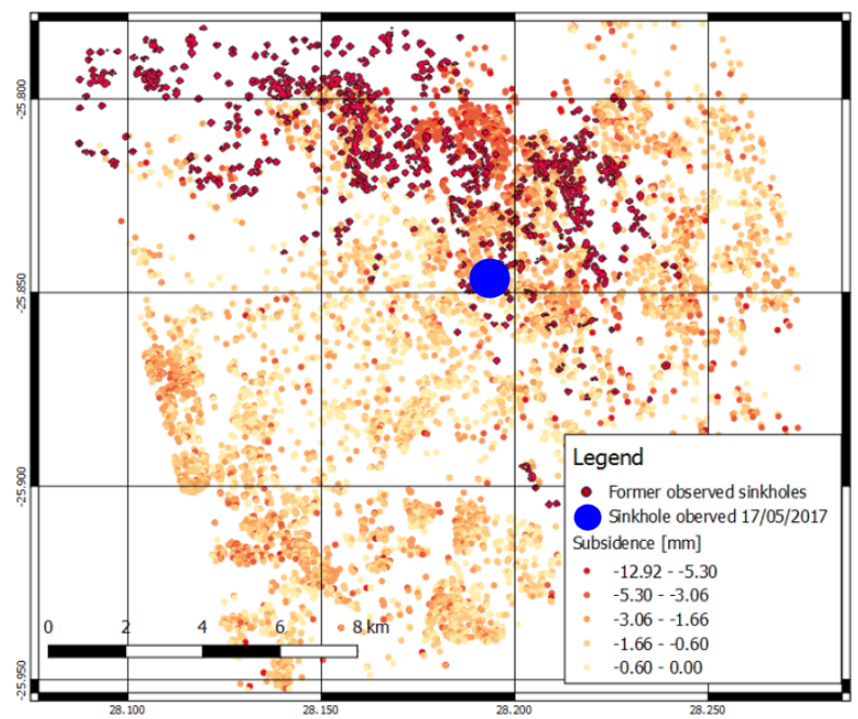

Figure 4. Yearly subsidence for the period May 2015-May 2017, COpenStreetMap contributors 2019. Distributed under a Creative Commons BY-SA License. Planet dump (Data file from 1 October 2019 of database Geofabrik). Retrieved from https://planet. openstreetmap.org.

was intensely built up. The total number of the processed points was 15370 (Fig. 3). PS displacement are measured along the satellite LOS, i.e. the sensor looking direction. The year displacement velocities, for the sensing period appear spatially homogeneous, decreasing with negative values (subsidence) to the N (Fig. 4).

The range of the vertical displacement is of -5 to $-12 \mathrm{~mm} \mathrm{yr}^{-1}$. The PS to the centre and $\mathrm{S}$ of study area were subsiding up to $-3 \mathrm{~mm} \mathrm{yr}^{-1}$. The observed increase of subsidence close to the SW outskirts attributed to noise and processing artefacts.

\section{Discussion and conclusions}

The maximum subsidence velocity of $-12 \mathrm{~mm} \mathrm{yr}^{-1}$ was observed to the $\mathrm{N}$ part of Centurion, which agrees to the high spatial density distribution of former sinkholes. The $\mathrm{N}$ of study area belongs to a high extend to the South Africa Spatial Forces. However, in the vicinity of sinkhole which occurred on corner of Jean and Gerhardt street (blue circle on Fig. 5), no significant linear subsidence was observed. Theron (2017) and Intrieri et al. (2015) concur that in the case of sinkholes, deformation in the order of a few $\mathrm{mm}$ to $\mathrm{cm}$ are expected to occur days, months or even years before the failure. In general, measurable deformation has been observed before major displacement occurs, although the main limitation lies in the opportunity to observe such deformation. Latest observation of ground movement before sinkhole development revealed accelerating character of ground movements (Malinowska et al., 2017). PS technique assumes that

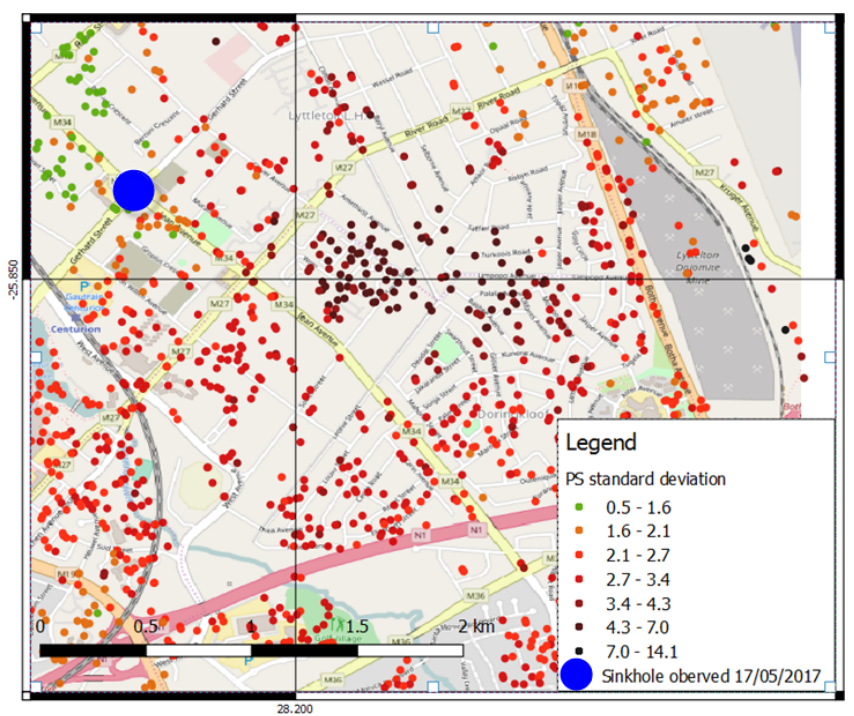

Figure 5. Standard deviation of PS points in the vicinity of the corner Jean and Gerhardt street, (O) OpenStreetMap contributors 2019. Distributed under a Creative Commons BY-SA License. Planet dump (Data file from 1 October 2019 of database Geofabrik). Retrieved from https://planet.openstreetmap.org.

observed ground displacement has a linear character. When the process becomes non-linear the values of the observed standard deviation is higher. The analysis of the spatial distribution of standard deviation led to the identification of a zone with standard deviation higher than $-7 \mathrm{~mm} \mathrm{yr}^{-1}$ (Fig. 5), in the vicinity of the recent sinkhole event.

Consistency of PS points distribution with high standard deviation was very high.

The PSInSAR analysis was carried out using ascending and descending SAR images from Sentinel-1 between May 2015 and May 2017. The PSInSAR study for the temporal interval preceding sinkhole occurrence on the 17 May 2017 shows subsiding and stable zones. Most of Centurion region seems to be relatively stable with an average displacement velocity of $6 \mathrm{~mm} \mathrm{yr}^{-1}$. In the $\mathrm{N}$ of study area, the mean annual subsidence reached $-12 \mathrm{~mm} \mathrm{yr}^{-1}$.

The displacement in that area is linear and the standard deviation does not exceed $-2.0 \mathrm{~mm} \mathrm{yr}^{-1}$. Observed ground movement in the vicinity of sinkhole which occurred on the 17 May 2017 is inferred that did not have linear character. Due to the known widespread presence of several sinkholes in the Centurion area, it is tempting to associate these localized, isolated displacement time series with the precursory movements associated with the nearby, possibly undetected sinkhole.

Comparison between levelling mean velocities and PS mean vertical velocities is planned for comparison and validation of PSInSar measured displacement. Further measurements are planned in the $\mathrm{N}$ of the study area. 
As demonstrated in the present study, SAR interferometry may represent an essential tool to detect displacement associated with sinkhole presence. Such studies can be used to influence the engineering design choices for the risk mitigation in urbanized areas characterized by the presence of soluble rocks.

Data availability. The data are not publicly accessible due to the fact that it was a part of ESA research grant No.39917, "Monitoring and early warning of sinkhole development using smart sensors and InSAR".

Author contributions. MF conceived and presented idea, wrote the paper in consultation with AM, received funding form WRC. TW, analysed the data, RH, analysed the data $\mathrm{HG}$, responsible for field studies, AM, directed and funded part of the project, wrote part of the paper, received funding from National Science Centre, Poland. All authors provided critical feedback and helped shape the research, analysis and manuscript.

Competing interests. The authors declare that they have no conflict of interest.

Special issue statement. This article is part of the special issue "TISOLS: the Tenth International Symposium On Land Subsidence - living with subsidence". It is a result of the Tenth International Symposium on Land Subsidence, Delft, the Netherlands, 17-21 May 2021.

Acknowledgements. This research has been supported by the National Science Centre, Poland, Research grant no. UMO2014/15/B/ST10/04892, and the Water Research Commission in South Africa no. K5 2937. This work presents results from the European Space Agency (ESA). Product of TerraSAR-X and TanDEM-X/X-Band SAR.

The authors wish to thank the reviewers for the comments and constructive feedback that improved the quality of the paper.

Financial support. This research has been supported by the Water Research Commission in South Africa (grant no. K5 2937) and the National Science Centre, Poland, Research (grant no. UMO2014/15/B/ST10/04892).

\section{References}

Baer, G., Magen, Y., Nof, R. N., Raz, E., Lyakhovsky, V., and Shalev, E.: InSAR measurements and viscoelastic modelling of sinkhole precursory subsidence: Implications for sinkhole formation, early warning, and sediment properties, J. Geophys. Res.Earth Surf., 123, 678-693, 2018.
Buttrick, D. B., Trollip, N. Y. G., Watermeyer, R. B., Pieterse, N. D., and Gerber, A. G.: A performance-based approach to dolomite risk management, Environ. Earth Sci., 64, 1127-1138, 2011.

Colesanti, C., Ferretti, A., Prati, C., and Rocca, F.: Monitoring landslides and tectonic motions with the Permanent Scatterers Technique, Eng. Geol., 68, 3-14, 2003.

De Bruyn, I. A. and Bell, F. G.: The occurrence of sinkholes and subsidence depressions in the Far West Rand and Gauteng Province, South Africa and their engineering implications, Environ. Eng. Geosci., 7, 281295, https://doi.org/10.2113/gseegeosci.7.3.281, 2001.

Dippenaar, M., van Rooy, L., and Diamond, R.: Engineering, hydrogeological and vadose zone hydrological aspects of Proterozoic dolomites (South Africa), J. Afr. Earth Sci., 150, 511-521, 2019.

ESA (European Space Agency): Sentinel-1 User Handbook, September 2013: ESA User Guide; GMES-S1OP-EOPG-TN-130001, European Space Agency, Paris, France, p. 80, 2017.

Ferretti, A., Fumagalli, A., Novali, F., Prati, C., Rocca, F., and Rucci, A.: A New Algorithm for Processing Interferometric Data-stacks: SqueeSAR, IEEE T. Geosci. Remote, 49, 34603470, 2011.

Gutiérrez, F., Galve, J., Lucha, P., Bonachea, J., Jorda, L., and Jordá, R.: Investigation of a large collapse sinkhole affecting a multistorey building by means of geophysics and the trenching technique (Zaragoza city, NE Spain), Environ. Geol., 58, 1107-1122, https://doi.org/10.1007/s00254-008-1590-8, 2009.

Gutiérrez, F., Parise, M., De Waele, J., and Jourde, H.: A review on natural and human-induced geohazards and impacts in karst, Earth Sci. Rev., 138, 61-88, https://doi.org/10.1016/j.earscirev.2014.08.002, 2014.

Gutiérrez, F., Calvo, A. B., Carbonel, D., Desir, G., Sevil, G., Guerrero, J., Fernández, A. M., Karamplaglidis, T., Arnay, A. G., and Fabregat, I.: Review on sinkhole monitoring and performance of remediation measures by high-precision leveling and terrestrial laser scanner in the salt karst of the Ebro Valley, Spain, Engineering Geology 248, 283-308, 2019.

Intrieri, E., Gigli, G., Nocentini, M., Lombardi, L., Mugnai, F., Fidolini, F., and Casagli, N.: Sinkhole monitoring and early warning: An experimental and successful GB-InSAR application, Geomorphology, 241, 304-314, 2015.

Malinowska, A., Witkowski, W., Hejmanowski, R., Chang, L., Hanssen, R., F., and Van Leijen, F. J.: Early detection of sinkholes applying persistent scattered interferometry (PSI), XVIII Mining workshop, 2017.

Malinowska, A., Witkowski, W., Hejmanowski, R., Chang, L., Hanssen, R., F., and Van Leijen, F. J.: Sinkhole occurrence monitoring over shallow abandoned coal mines with satellitebased persistent scatterer interferometry, Eng. Geol., 1-20, https://doi.org/10.1016/j.enggeo.2019.105336, 2019.

Nof, R., Abelson, M, Raz, E., Magen, Y., Atzori, S., Salvi, S., and Baer, G.: SAR Interferometry for Sinkhole Early Warning and Susceptibility Assessment along the Dead Sea, Israel, Remote Sens. 11, 1-34, https://doi.org/10.3390/rs11010089, 2019.

Oosthuizen, A. C. and Richardson, S.: Sinkholes and subsidence in South Africa, Council for Geoscience, 1-5, 2011.

Rosen, P. A., Hensley, S., Joughin, I. R., Li, F. K., Madsen, S. R., Rodriguez, E., and Goldstein, R. M.: Synthetic aperture Radar interferometry, Proc. IEEE., 88, 333-382, 2000. 
SANS1936 (South African National Standard): 1936-1/2/3/4, Development of Dolomite Land, 1st Edn., 2012.

Sowers, G. F.: Building on sinkholes: Design and construction of foundations in karst terrain, ASCE, NY, 1996.

Theron, A., Engelbrecht, J., Kemp, J., Kleynhans, W., and Turnbull, T.: Detection of Sinkhole Precursors through SAR Interferometry: Radar and Geological Considerations, IEEE Geosci. Remote S., 14, 871-875, 2017.
Vaccari, A., Stuecheli, M., Bruckno, B., Hoppe, E., and Acton, S. T.: Detection of geophysical features in InSAR point cloud data sets using spatiotemporal models, Int. J. Remote Sens., 34, 82158234, 2013. 